\title{
THE SIMILARITY OF HUSBANDS' AND WIVES' POLITICAL VIEWS
}

\author{
RICHARD G. NIEMI \\ University of Rochester \\ ROMAN HEDGES \\ State University of New York, Albany \\ M. KENT JENNINGS \\ University of Michigan
}

\begin{abstract}
Even in these days of the women's liberation movement, the Eassumption of marital homogeneity of political values is rarely challenged. Wives may be more involved in politics than ever before, and there are a few outstanding examples of families in which the wife is clearly politically dominant. Even so, the assumption is retained that husbands and wives rarely differ politically (Miller, 1970).

Yet, in fact, there is very little direct evidence to support or deny couple homogeneity at the mass level. ${ }^{1}$ What evidence does exist consists of questionable inferences from aggregate data showing few sex differences in political attitudes and of data showing that husbands and wives typically support the same political party.

Our first task, then, is to provide some evidence of the scope and depth of spouse agreement about political affairs. More than this, however, we also want to delve into the more difficult


matter of explaining variations in levels of agreement. We are well aware of the hazards of approaching this question without panel data covering the pre - to postmarital period. Insofar as possible, however, we will seek to determine whether selection, mutual socialization, or something else accounts for the similarity which is found.

\section{STUDY DESIGN}

The data were gathered in 1965 as part of a larger study of political socialization among high school seniors. The core of the study was a national probability sample of 1669 seniors. One-third of the seniors were randomly designated for motheronly interviews, one-third for father-only interviews, and one-third for both mother and father. It is the latter group of husbands and wives that we make use of here. Due largely to the anticipated loss from one-parent families, interviews were completed with 430 husband-wife pairs (with a weighted $\mathrm{N}$ of 531).

The sample can be treated as a representative cross-section of couples having high school seniors. It should be noted that the sample has some class bias (compared to the population of all parental couples) since high school dropouts were not included in the student sample, and an age bias since most of the couples are between the ages of 35-55.

\section{COUPLE HOMOGENEITY}

Our data permit an assessment of homogeneity in four different political areas: trust and cosmopolitanism, partisanship and voting, attitudes on specific issues, and evaluations of sociopolitical groups. For comparison, several nonpolitical orientations will also be considered. Briefly, political trust is a five-item Guttman scale $(C R=.93)$ based on questions dealing with the conduct of the national government. ${ }^{2}$ Cosmo- 
politanism is a scale which ranks respondents in terms of their interest and attention to different levels of government, ranging from extreme localist to internationalist. Party identification is based on the standard Michigan questions yielding seven categories from strong Democrat to strong Republican. Issue questions were either of the agree-disagree type or "forcedchoice" questions where respondents were given two opposing points of view and asked which one was closest to their own point of view. Group evaluations are "thermometer" items, where respondents rated each of eight groups on a scale ranging from zero to 100 . Of the nonpolitical items, social trust is a three-item Guttman scale ( $C R=.94)$, the religious Fundamentalism question asks for an interpretation of the Bible ranging from "God's Word" to "irrelevant," and the final question asks whether teenagers are better, worse, or about the same as they used to be.

In the left-hand column of Table 1 we provide percentages of husbands and wives who show perfect agreement on each of the items mentioned above. ${ }^{3}$ (The correlations in Table 1 will be referred to later.) For a number of the items perfect agreement is a rather stringent requirement because the measures divide respondents rather finely. Therefore, in a footnote to the table, we provide the percentage of pairs showing near-perfect agreement on these items. For all items except partisanship, the "near-perfect" agreement figure represents perfect agreement or disagreement of no more than one category. The party identification figure represents perfect agreement using only the three-way division into Democrats, independents, and Republicans.

Interpretation of these figures is complicated by several considerations. The first such consideration concerns the possible lack of respondent interest in specific issues. The percentages in Table 1 are based on all pairs in which both the husband and wife expressed an opinion. But we know that in some cases individuals have little or no interest in a given issue. If we include these people in our calculations (adding to the amount of agreement only when both the husband and wife 
[136] AMERICAN POLITICS QUARTERLY / APRIL 1977

TABLE 1

Similarity of Husbands' and Wives'

Political Orientations

\begin{tabular}{|c|c|c|c|c|c|}
\hline Topic & $\begin{array}{l}\text { Perce } \\
\text { Pairs }\end{array}$ & $\begin{array}{l}\text { at of } \\
\text { Agreeing }\end{array}$ & & $\begin{array}{l}\tau_{b} \text { Correla } \\
\text { bettween } H \\
\text { and wives }\end{array}$ & $\begin{array}{l}\text { at lon } \\
\text { lusbands' } \\
3^{\prime} \text { Opinions }\end{array}$ \\
\hline $\begin{array}{l}\text { General Orfentat ions } \\
\text { Polltical crust } \\
\text { Cosmopolitantsi }\end{array}$ & $\begin{array}{l}30 x \\
26\end{array}$ & $\begin{array}{l}(515)^{b} \\
(350)\end{array}$ & & & $\begin{array}{l}.22 \\
.28\end{array}$ \\
\hline $\begin{array}{l}\text { Partisanship } \\
1964 \text { presidential vote } \\
\text { or preference } \\
\text { Party identification }\end{array}$ & $\begin{array}{l}89 \\
44\end{array}$ & $\begin{array}{l}(474) \\
(507)\end{array}$ & & & $\begin{array}{l}.78 \\
.59\end{array}$ \\
\hline $\begin{array}{l}\text { Issue Positions } \\
\text { School prayers } \\
\text { Speeches against churches } \\
\text { Ne1ghborhood integration } \\
\text { Communists hold of fice } \\
\text { School integration } \\
\text { 18-year-old vote }\end{array}$ & $\begin{array}{l}81 \\
71 \\
69 \\
66 \\
64 \\
64\end{array}$ & $\begin{array}{l}(462) \\
(527) \\
(523) \\
(514) \\
(451) \\
(498)\end{array}$ & $=$ & & $\begin{array}{l}.47 \\
.22 \\
.43 \\
.28 \\
.62 \\
.29\end{array}$ \\
\hline $\begin{array}{l}\text { Group Evaluations } \\
\text { Whites } \\
\text { Protestants } \\
\text { Catholics } \\
\text { Jews } \\
\text { Southerners } \\
\text { Negross } \\
\text { Big business } \\
\text { Labor unions }\end{array}$ & $\begin{array}{l}42 \\
41 \\
36 \\
35 \\
31 \\
30 \\
24 \\
24\end{array}$ & $\begin{array}{l}(518) \\
(523) \\
(520) \\
(520) \\
(519) \\
(518) \\
(516) \\
(519)\end{array}$ & . & 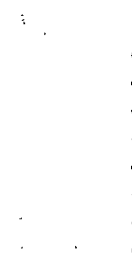 & $\begin{array}{l}.24 \\
.23 \\
.39 \\
.31 \\
.35 \\
.27 \\
.23 \\
.41\end{array}$ \\
\hline $\begin{array}{l}\text { Nonpolitical Orientations } \\
\text { Religion (Prot., } \\
\text { Cath., Jew, other) } \\
\text { Interpretation of Bible } \\
\text { Soclal trust } \\
\text { Teenagers "going to the } \\
\text { dogs" }\end{array}$ & $\begin{array}{l}95 \\
59 \\
57 \\
55\end{array}$ & $\begin{array}{l}(510) \\
(513) \\
(528) \\
(491)\end{array}$ & . & & $\begin{array}{l}. \overline{34} \\
.21 \\
.21\end{array}$ \\
\hline
\end{tabular}

a. "Near-perfect" agreement, as defined in the text, is as follows: political trust, $60 \%$; cosmopolitanism, $57 \%$; party identification, 76\%; group evaluations (in order), $69 \%$, $71,53,57,51,55,50,52$.

b. Numbers of cases on which the percentage is based.

disclaim interest), we would expect lower rates of agreement than those so far observed. Two of the issue questions allow us to make such a calculation. Each of these questions was prefaced by asking respondents whether they had enough interest in the issue to have an opinion. Including in the percentage agreement those who said, "no, they did not have an 
opinion" lowers agreement on the school integration issue to $56 \%$ and on the school prayer issue to $71 \%$.

A second consideration which must be attached to the figures in Table 1 is the extent of extreme disagreement. A good illustration is the case of partisanship. Whereas Table 1 indicates that over half of the husbands and wives disagree at least marginally and a fourth disagree even in the three-way classification, one finds that only $7 \%$ of the families include both a Republican and Democratic spouse. The remainder includes various combinations of partisans and independents. Similarly, even though the question on school integration and school prayers did not allow an intermediate category, a number of people took this option by answering "it depends." Diametrically opposed views are taken only by $18 \%$ and $11 \%$ on the integration and prayer issues, respectively. The same point could be made about each of the other orientations. Extreme disagreement between spouses is much less rare than some minimal sort of disagreement.

Bearing all of these factors in mind, the figures in Table 1 indicate to us that the assumption of couple homogeneity is indeed quite well founded. Even when the measures are finely calibrated, a quarter or more of the couples agree exactly. When a reasonable tolerance for minor discrepancies is allowed, at least three-fifths of the husband-wife pairs show agreement in their expressed viewpoints. ${ }^{4}$ And of the remainder, far fewer of the husbands and wives show extreme disagreement when some "moderate" attitude is permitted. Moreover, the similarity of political attitudes compares quite favorably with agreement about nonpolitical orientations.

At the same time, the degree of unanimity among husbands and wives should by no means be exaggerated. Only in voting behavior and religious affiliation was agreement extraordinarily high. This suggests to us an important conclusion. There exists within families a previously unrecognized potential for changes of attitudes and behavior. Were husbands and wives in more complete accord in their thinking, the mutual support they provide each other would make it more difficult for either of 
them to change their viewpoints. Given some disagreement, however, an opening wedge already exists for attitudinal and behavioral change. Of course, many of the disagreements are only moderate, and, as we noted, some arise simply because of indifference on the part of one spouse. But to describe a situation in which most husbands and wives have at least minimally divergent viewpoints on any given issue, and in which up to two-fifths have more than minimal disagreements, is to suggest a family political structure less monolithic than that traditionally portrayed.

Moreover, it is clear that if we look across issues we find disagreement about some issue(s) among nearly all couples. A simple way of observing this is to create an index which is the percentage of items on which couples agree. Using the ten political topics in Table 1, excluding group evaluations, each couple is given a score ranging from zero, representing no agreement, through 100 , representing agreement on every issue. The distribution of husband-wife pairs on this index is given in Figure 1. Many families show more than an occasional

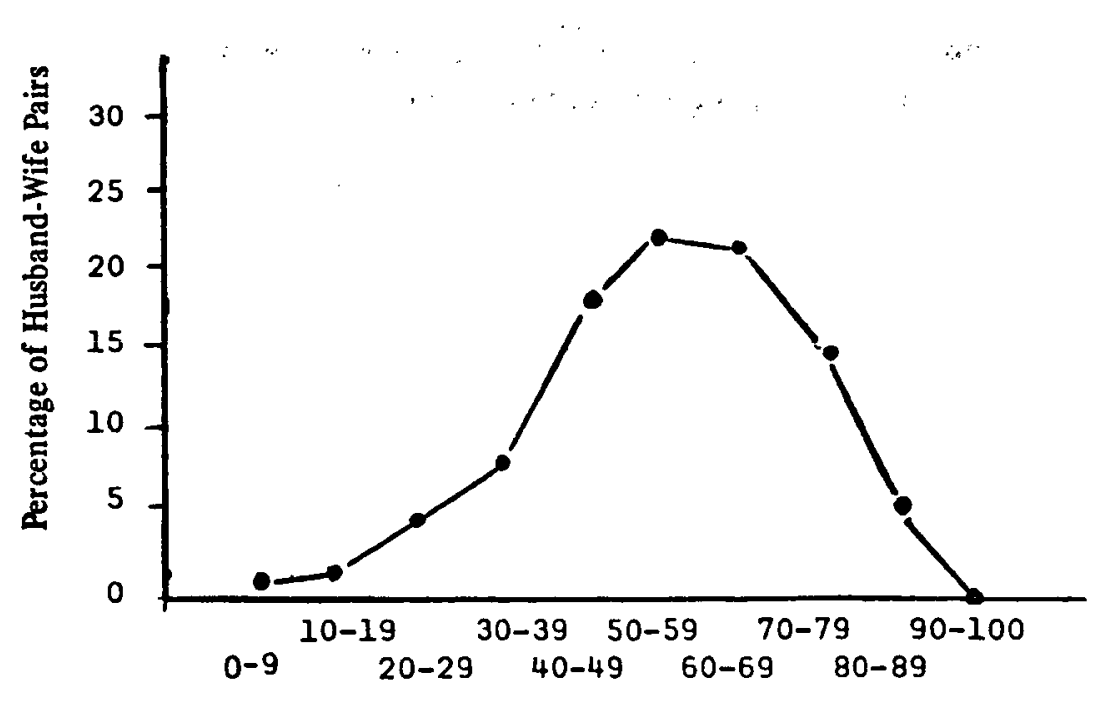

Percentage of Items on Which Husband and Wife Agree

Figure 1: Distribution of Husband-Wife Pairs According to Amount of Agreement 
disagreement. In fact, some $32 \%$ of the families show minimal or greater disagreement on more than half of the orientations. An additional $13 \%$ of the pairs disagree on exactly half of the orientations.

This figure, then, confirms the conclusion drawn on the basis of the separate items. Husbands and wives are characterized to a large extent by similarity of political orientations. But their similarity is not so complete that it prevents spouses from being a potentially dynamic component in the development and maintenance of political attitudes.

\section{DETERMINANTS OF HOMOGENEITY}

\section{EXPECTED AGREEMENT}

Much of the agreement found among husband-wife pairs may be attributable to the general agreement among males and females. As a test of this possibility, correlations were calculated between husbands' and wives' opinions. Even if actual agreement is very high, the correlations will be zero if the amount of agreement is no higher than what would be expected by chance. In addition, the correlation that we will use is relatively unaffected by the number of response categories, a useful consideration when the number of responses varies as it does here.

The correlations between husbands' and wives' attitudes are presented in the right-hand column of Table 1. The distinctiveness of voting behavior stands out clearly, even apart from partisanship. Husbands and wives vote much more similarly than one would expect if their behavior were statistically independent. Husbands' and wives' partisan feelings, while less associated than their votes, also show considerably more similarity than independence would suggest. On the specific issues the highest correlations are for the most concrete, immediate issues of integration and school prayers. The more removed and abstract issues of communists holding office and 
of free speech, and even the 18-year old vote, which was not an immediate concern in 1965, show considerably reduced correlations. Political trust and cosmopolitanism are also characterized by modest correlations. ${ }^{5}$

Overall these correlations indicate that husbands and wives are certainly more similar than one would expect if their views were statistically independent. For contrast one might compare the figures representing student-parent agreement. In every case the husband-wife correlation is higher, usually by .1 to .2 (Jennings and Niemi, 1974: 155). Yet they also indicate that when expected agreement is considered, husbands' and wives' attitudes are far from completely coterminous with their spouses' viewpoints.

Thus, while considering determinants of couple homogeneity, we must keep in mind that a good deal of the observed similarity can be attributed to what would be expected by chance. Our strategy will be to look for characteristics which are related to the correlations between husbands' and wives' attitudes-that is, to the degree to which husbands and wives agree more than is randomly expected-and not simply to the level of agreement per se.

\section{SELECTION OR MUTUAL SOCIALIZATION}

Obviously a panel design would be most appropriate for distinguishing between these contrasting explanations for parental homogeneity. Suitable panels are so rare, however, that we must approach the matter in as adequate a manner as possible with cross-sectional studies. Within these design limits, several measures provide what seems to be a good way of distinguishing between the two explanations. On the one hand, suppose the similarity between spouses were due primarily to selection effects. If we control for relevant background characteristics, we should find that husbands and wives are more similar when their backgrounds are more alike. Theoretically, the most relevant background factors are those which are related to the attitudes or behavior in question and which, conceivably at 
least, are widely used in determining marriage partners. In contrast, suppose the explanation for husband-wife homogeneity was mutual socialization. Since mutual influence is dependent upon interaction and exchange, frequent discussions of political topics would lead to increased homogeneity.

Curiously, the results do not strongly support either of these explanations, though they are consistent with the selection hypothesis in regard to party identification and the mutual socialization model for those who discuss politics very frequently. Considering selection effects first, we related the background factors of education, region, social class when growing up, size of town or city in which one grew up, religion, and partisan background (the husbands' and wives' fathers' party identification) to similarity of current attitudes. In each case, except that of education, we selectively sought effects where they were most likely to occur. ${ }^{6}$ Since education is related to so many political orientations, we looked for potential effects of this factor on all of the orientations given in Table 1.

Although there were isolated instances in which couples from dissimilar backgrounds had less similar attitudes, there was only one instance in which a consistent, explicable effect was observed.' When their fathers had identical loyalties, the correlations between spouses' identifications were .59 and .61 for those of Democratic and Republican backgrounds, respectively. (There was only one case in which both fathers were independent.) But when the fathers differed, including partisanindependent mixes, the husband-wife correlation dropped to .44. When both fathers had the same party loyalties, the correlations between the husbands' and wives' votes were .80 and .91 for Democratic and Republican fathers, respectively. When the fathers differed, the correlation dropped to .75. Thus the similarity of party backgrounds does seem to affect the homogeneity of marriage partners' partisanship and voting. ${ }^{8}$ But this selection effect does not apparently extend to other political orientations or other background characteristics. 
Though the data examined thus far do not support the selection hypothesis, we should search more deeply for possible selection effects. In many cases where we categorized couples as coming from different backgrounds, the degree of difference was minimal-for example, a college graduate married to someone with only a partial college education. It might be the case that if we narrowed our view to couples differing substantially in background that we would observe a consistent drop in political agreement.

Educational background, social class, and partisanship were used to test this because they are monotonically related to a number of political orientations (so that individuals from very different backgrounds are more likely to have very different political views) and because there are enough couples with reasonably large background differences. We used a six-step education classification and an eight-step occupational classification for the husbands' and wives' fathers. In each case we took husbands and wives whose background differed by at least two levels and compared their degree of similarity with that of homogeneous couples. For partisanship, extreme mixes were those in which the father of one spouse was a Democrat and the other a Republican. Even in these more extreme cases, however, similarity of political views was related to homogeneity of background only in the instance of partisanship-where the correlations between husbands' and wives' party identification and vote dropped slightly below those noted for the mixed case earlier. Thus, even relatively gross dissimilarities in backgrounds failed to result in consistently lower husband-wife agreement.

Now let us turn to the frequency of husband-wife discussions of political affairs and see whether there is evidence to support the mutual socialization model. We will use the frequency of political discussions as reported by both spouses. ${ }^{9}$ The data (not shown) consist of a set of five correlations, one for each frequency of discussions, for each of the attitudes (excluding group evaluations) listed in Table 1 . If mutual socialization were the explanation for the level of husband-wife similarity, we would expect the correlations to decline along with the 
frequency of political discussions. While something like this pattern is observed in one or two cases, there is no common pattern to the variations in correlations. Similarly, no common pattern emerges from a comparison of husband and wife attitudes when spouses report getting along with each other very well, pretty well, or not very well. Contrary to what the mutual socialization model would suggest, there is no gain in the similarity as husbands and wives get along better. ${ }^{10}$

As in the case of background characteristics, let us push the matter of political discussions to an extreme. Specifically, let us divide husband-wife pairs into a small group (10\% of the sample) in which both husband and wife report very frequent political conversations, and a small group (10\%) at the other extreme in which both spouses allege that they "never" discuss politics and public affairs, with the remaining $80 \%$ constituting a heterogeneous middle group. Do we now find a pattern of higher agreement where discussions are frequent and lower agreement where they are rare?

The results (Table 2 ) suggest that very frequent conversations do to some extent raise agreement levels between husbands' and wives' attitudes. If we compare the frequent talkers with the large middle group or with the entire set of husbands and wives (Table 1), we find higher correlations in virtually every instance. Moreover, the absolute levels of the correlations are rather high for this group, especially on the more concrete issues. On the other hand, those who profess very few political conversations are not correspondingly lower in their agreement levels. Indeed, in three cases they are more similar than the very frequent talkers!

There is, then, a degree of positive support for the mutual socialization model. At one extreme we do find husbands and wives who are considerably more alike than chance would predict and who exceed expected levels of agreement by substantially more than the rest of the population. But we must remember that this conclusion applies to only a tenth of the couples; for the remainder the mutual socialization model seems no more appropriate than the selection hypothesis. 
[144] AMERICAN POLITICS QUARTERLY / APRIL 1977

TABLE 2

Similarity of Husbands' and Wives' Political Attitudes Controlling for Frequency of Political Discussions

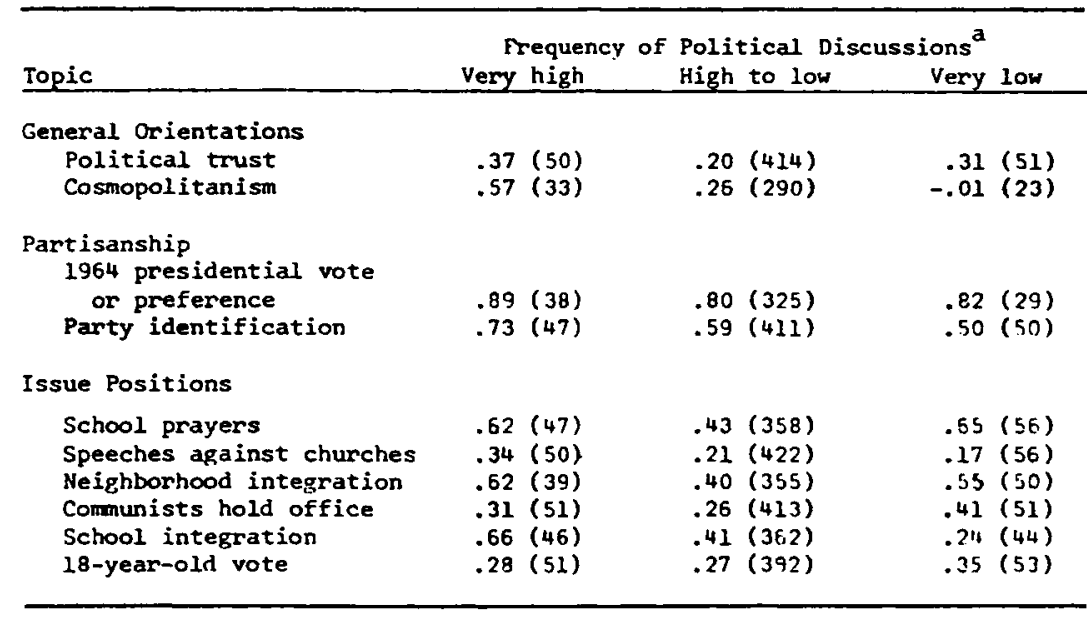

a. Very high: both husband and wife report having discussions of public affairs and politics "very often." Very low: both report that they "don't talk" about public affairs and politics. High to low: all other husband-wife pairs.

\section{ALTERNATIVE EXPLANATIONS}

If neither selection nor mutual socialization adequately explains the observed similarity of husbands and wives (above and beyond what would be expected by chance), how might this homogeneity be explained? One possibility is simply that the everyday similarities experienced by couples serve to heighten their political homogeneity even in the absence of any mutual influence. Husbands and wives, more than a randomly chosen pair, read the same newspapers, see the same television programs, listen to the same friends, and in general share the same experiences. To the extent that these factors influence a person's attitudes, spouses could be expected to grow more similar as time passed.

It is also possible that selection and mutual socialization are appropriate explanations, but that they do not operate in the manner described above. Selection, for example, may occur on the basis of attitudinal agreement rather than similarity of 
background characteristics. We doubt that selection of spouses is based on explicitly political attitudes, but similarity of broad social viewpoints would probably be sufficient to guarantee at least a moderate degree of concordance on specific political issues. Mutual socialization could also operate differently than as described above, occurring primarily in the early years of marriage. ${ }^{11}$ Since most of the couples in our sample had been married at least 17 years, there would be little or no residual impact to observe at this point. Alternatively, mutual socialization may occur slowly but steadily even in the absence of many political conversations. Thus, after 17 years there could reasonably be mutual accord even among spouses who rarely discuss politics.

To probe these various explanations would require a different study design than that employed here. Until that is done we will not adequately be able to distinguish among them. Nonetheless, our analysis has cast doubt on selection effects, except for the domains of partisanship and voting, and has suggested that mutual socialization later in marriage affects at most a small portion of the population. It also indicates that much of the agreement between husbands and wives is artifactual; it would exist even in the absence of mutual selection or influence.

\section{CONCLUSION}

Gross generalizations about couple homogeneity based on the similarity of voting behavior need to be qualified substantially. At the same time, there is no gainsaying the presence of widespread agreement, especially if the requirements of exact agreement are relaxed. These relatively high rates of agreement (as distinct from the pair correlations) have two important implications. At the level of husband-wife pairs it means that one partner ordinarily can look to the other for support and reinforcement or-at the very least-not be in direct conflict with that partner. To the extent that stability and consonance are desired attributes, the agreement levels provide a personally 
satisfying environment. More significantly, these levels of agreement reduce the likelihood of change by either partner since there is a supportive, reinforcing environment at hand.

What should not be lost sight of, however, is that appreciable disagreement does exist across a variety of political attitudes. It is a rare couple that agrees on everything. The presence of nonsupportive environments would seem likely to produce the kinds of results of ten observed when primary group support is weak, namely, less consistent behavioral and attitudinal states.

The second implication of couple similarity lies in its role as a determinative factor in the successful transmission of political values from parents to children (Jennings and Niemi, 1974: ch. 6). If husbands and wives disagreed more frequently than we observed, we would expect an even weaker flow of political attitudes between generations than has been found. What we have been observing, therefore, is an important variable in understanding the process of political socialization. At the time of our data collection the rate of husband-wife agreement results in a picture of parental life devoid of much conflict over, or even much exchange of political ideas. But this need not always be so. And to the extent that this agreement is variable in other circumstances, we would look for concomitant variation in the transmission of parental values to the next generation.

\section{NOTES}

1. Politics is clearly not a major source of marital conflict. But this may be due to agreement between spouses or to the low salience of politics in comparison with more immediate concerns such as money and children. See Blood and Wolfe (1960).

2. Question wording is found in Jennings and Niemi (1974).

3. For percentage purposes, the thermometer ratings are always divided into the ten groups scored $0-9,10-19, \ldots, 90-99$.

4. The lower agreement rates on group evaluations may well be a function of measurement problems. See Niemi (1974: ch. 7).

5. The order of the correlations for group evaluations is very much dependent on the variance of the ratings for each group. Thus, for example, while husbands and 
wives agree that whites and Protestants rate highly (see Table 1), the variance in the ratings is so low that their responses show little correlation.

6. Region was considered with reference to items dealing with race and religion; social class with attitudes toward labor unions and big business, cosmopolitanism, and the "communist hold of fice" and "speeches against churches" issues; size of town with cosmopolitanism; religion with the school prayer and "speeches against churches" issues; partisan background with partisanship and voting.

7. In contrast to our results here, the educational background of husbands versus wives does have a considerable effect on political resources, interest, and participation. See Jennings and Niemi (1971).

8. A much more extensive investigation of this case is found in Beck and Jennings (1975).

9. There is a fair amount of disagreement between husbands and wives about the frequency of political conversations. Here we have combined the two reports into a simple index, though some analysis was performed, with the same results, using each spouse's responses separately. As another way of overcoming possible response unreliability, we will look at extreme cases below.

10. We put less eight on these latter results because of the greater possibility of response unreliabilities (Niemi, 1974: chs. 5 and 8).

11. However, studies of nonpolitical attitudes have found little relationship between length of marriage and husband-wife similarity (Kirkpatrick and Hobard, 1954; Kelly, 1961; Udry, Nelson, and Nelson, 1961).

\section{REFERENCES}

BECK, P. A. and M. K. JENNINGS (1975) "Parents as 'middle-persons' in political socialization." J. of Politics 37: 83-107.

BLOOD, R. O., J. and D. M. WOLFE (1960) Husbands and Wives. New York: Free Press.

JENNINGS, M. K. and R. G. NIEMI (1974) The Political Character of Adolescence. Princeton, NJ: Princeton Univ. Press.

- (1971) "The division of political labor between mothers and fathers." Amer. Pol. Sci. Rev. 65: 69-82.

KELLY, E. L. (1961) "The re-assessment of specific attitudes after twenty years." J. of Social Issues 17: 29-37.

KIRKPATRICK, C. and C. HOBART (1954) "Disagreement, disagreement estimate, and non-empathy imputations for intimacy groups varying from favorite date to married." Amer. Soc. Rev. 19: 10-19.

MILLER, W. E. (1970) "The political behavior of the electorate," in E. C. Dreyer and W. A. Rosenbaum (eds.) Political Opinion and Behavior. Belmont, CA: Wadsworth.

NIEMI, R. G. (1974) How Family Members Perceive Each Other. New Haven, CT: Yale Univ. Press.

UDRY, J. R., H. A. NELSON, and R. NELSON (1961) "An empirical investigation of some widely held belief about marital interaction." Marriage and Family Living 23: $388-390$. 


\section{[148] AMERICAN POLITICS QUARTERLY / APRIL 1977}

Richard G. Niemi is a Professor in the Department of Political Science of the University of Rochester, New York.

Roman Hedges is affiliated with the Department of Political Science of the State University of New York at Albany.

M. Kent Jennings is a Professor in the Department of Political Science of the University of Michigan, Ann Arbor and a member of the Editorial Board of American Politics Quarterly. 